\title{
The importance of a lifeboat-median artery forearm flap in Goldenhar Syndrome
}

\author{
Anna M. Jaźwiec ${ }^{1,2}$ [D $\cdot$ Ewa D. Komorowska Timek ${ }^{1,3}$ \\ Received: 5 June 2021 / Accepted: 13 August 2021 / Published online: 3 September 2021 \\ (c) The Author(s) 2021
}

\begin{abstract}
We present a case of a 32-year-old male with left-sided Goldenhar Syndrome and delta phalanx of the thumb, who was offered free tissue transfer from the forearm to address an intra-oral soft tissue deficiency. Despite the presence of appropriately developed right radial artery, used in previous facial reconstruction, the left radial artery occurred to be hypoplastic. He ultimately underwent free flap transfer based on the anomalous persistent left median artery. We suggest that in face of an unusual hand anatomy, flexible flap creation techniques that allow a lifeboat strategy of adjusting flap design should be considered preoperatively. Level of evidence: Level V, therapeutic study.
\end{abstract}

Keywords Median artery forearm flap · Vascular anomalies · Anomalous thumb · Goldenhar Syndrome

\section{Introduction}

The radial forearm flap is typically supplied by the radial artery and its perforators to the overlying skin [1]. Although the radial arterial system is rather consistent, rare anomalies have been reported. The radial artery has been noted to vary in site of origin [2,3], course [2], number and location of perforators $[4,5]$. Additionally, radial hypoplasia and aplasia have been previously described [6]. Typically, the median artery forms part of the main arterial supply to the hand within the first trimester [7-11]. Although the median artery regresses in $90 \%$ of population, it can sometimes be found running parallel to the median nerve into the carpal tunnel and contributing to the vascularization of the hand [7-12]. In case of the dominant median artery, the skin of the forearm can also be supported by the perforators stemming from this vessel, which is of great importance when designing a forearm-based flap [5].

Anna M. Jaźwiec

annamariajazwiec@gmail.com

1 Advanced Plastic Surgery, 3855 Burton Street SE, Suite A, Grand Rapids, MI 49546, USA

2 Medical University of Silesia, Katowice, Poland

3 College of Human Medicine, Michigan State University, East Lansing, MI, USA
Goldenhar Syndrome, also called oculoauriculovertebral dysplasia, refers to patients with the spectrum of anomalies including unilateral microtia, blepharoptosis, mandibular hypoplasia, microstomia, epibulbar tumors, and vertebral deformities [13]. Very rare limb anomalies occurring in Goldenhar Syndrome have never been described as arterial system anomalies or ipsilateral delta phalanx.

\section{Case report}

Our patient was a 32-year-old male who was born with left Goldenhar Syndrome. As a child, he underwent multiple reconstructive procedures of the facial skeleton. Six years prior to presentation, he sustained a self-inflicted gunshot wound to the mandible, which necessitated right osteocutaneous fibula and right radial forearm free flap transfers to reconstruct the defects.

He presented to our practice with an intra-oral soft tissue deficiency and drooling (Fig. 1). To address the shallow buccal sulcus and provide a lower lip sling, he was offered free tissue transfer from the left forearm, including the tendon of the palmaris longus to improve oral competence. The patient was found to have normal anatomy of the right forearm; 


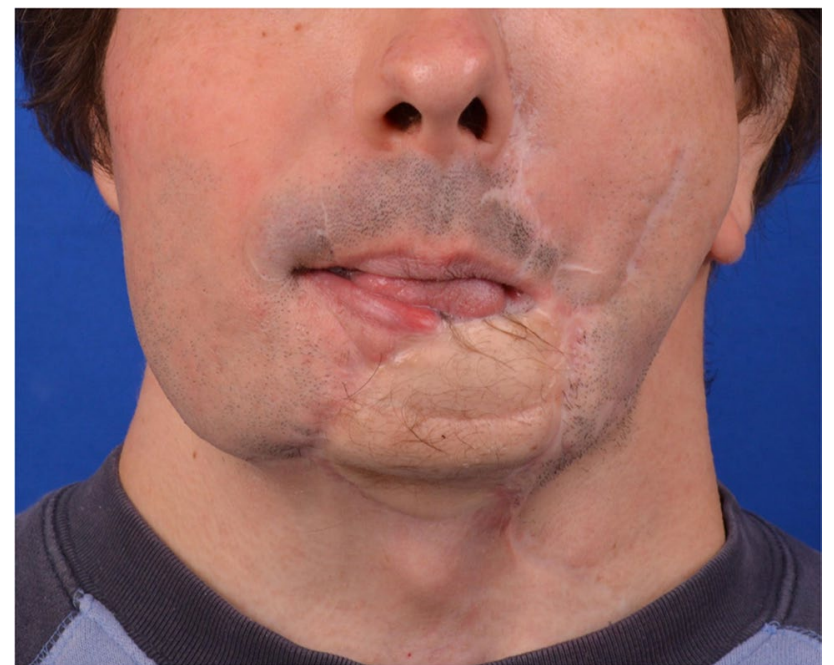

Fig. 1 Preoperative photograph of 32-year's old patient with Goldenhar Syndrome, depicting soft tissue deficiency and tightness of the lower lip

however, the left thumb appeared to be distorted harboring a delta phalanx (Fig. 2).
Pre-operative Allen's test using Doppler machine revealed adequate hand perfusion via the ulnar artery and questionable deep palmar arch perfusion from the radial artery. Intra-operatively, Doppler signal over the radial artery appeared weak and followed a linear vessel pattern in a usual location. The skin paddle of the flap was designed over the marked radial artery and tendon of the palmaris longus. The dissection revealed multiple perforators arising from the area above the median nerve. To allow the dissection to proceed radially, some of these perforators were ligated. Surprisingly, instead of the expected anatomy, a sizeable vascular bundle overlying the median nerve was identified. The median artery was found to originate from the proximal ulnar artery, running directly above the median nerve into the carpal tunnel, $2 \mathrm{~mm}$ in diameter (Figs. 3 and 4 ). Thus, the remaining perforators connecting the median artery and the skin paddle were meticulously preserved. A vestigial radial artery originated from the distal brachial artery and continued only to the midportion of the forearm, without any perforators. After the vessels were identified and the viability of the hand was assured, the median artery was ligated distally, and the flap was raised from distal to proximal liberating the artery together with median veins from the intact median nerve. The flap was then transferred to the recipient site
Fig. 2 Figure shows 32-year's old patient's left hand with distorted thumb and an X-ray revealing harbored deltaphalanx. The arrow points at the trapezoidal distal phalanx

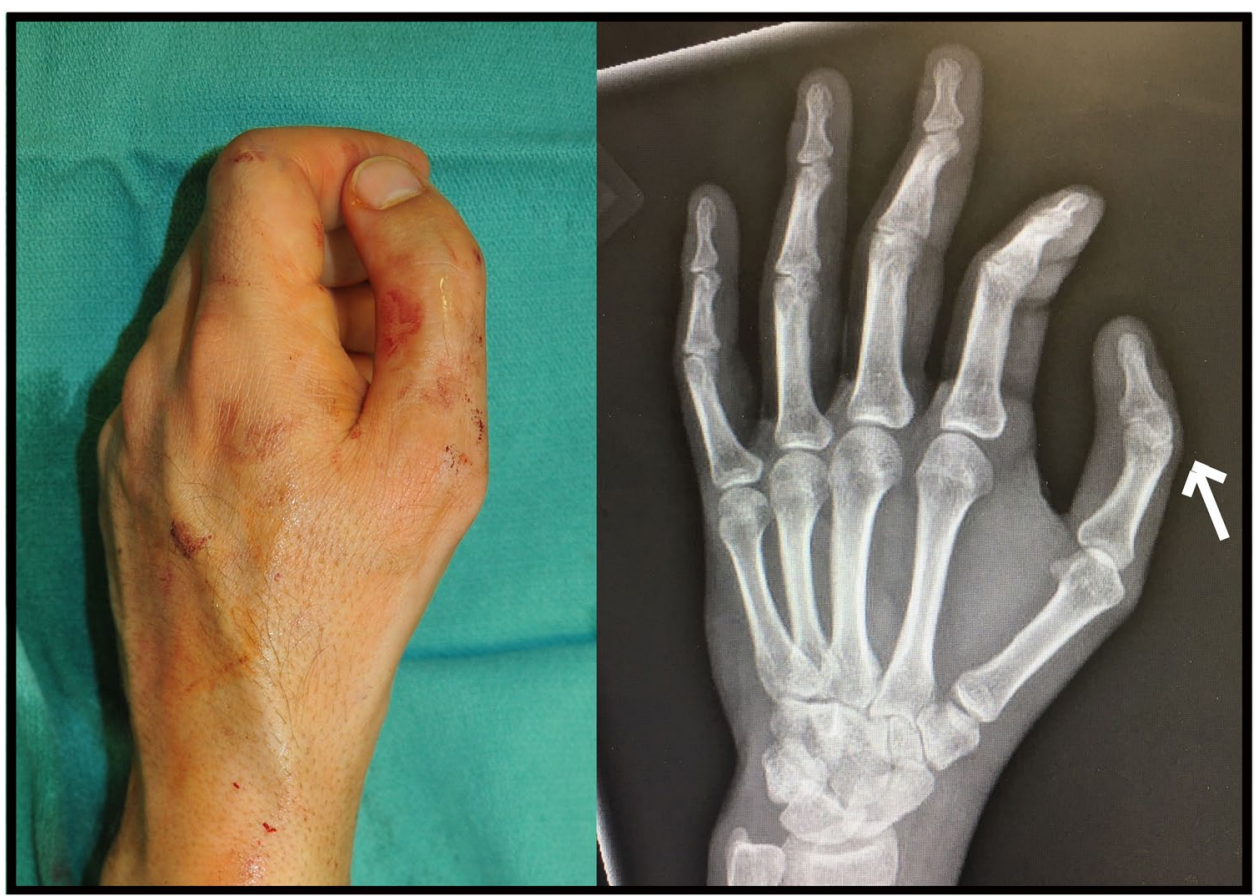




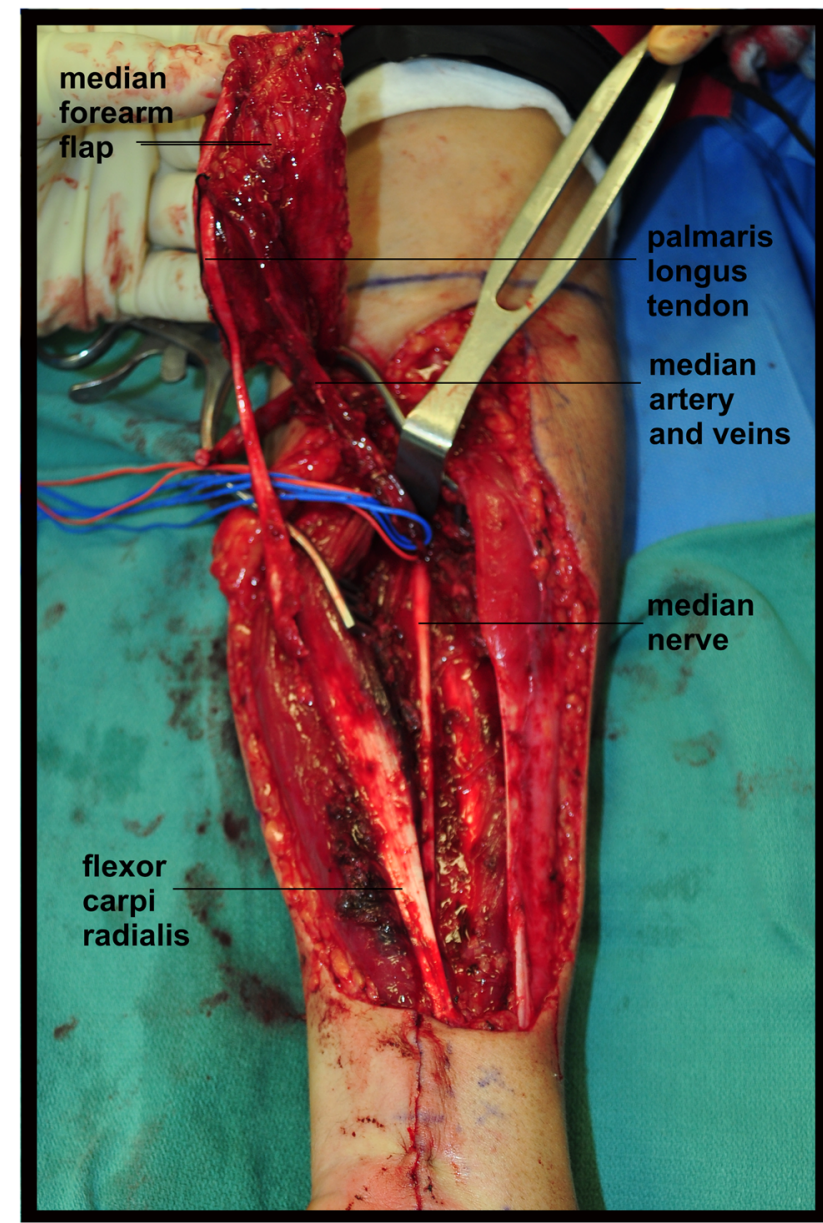

Fig. 3 Intraoperative appearance of the patient's left forearm during median free flap harvest

and the median vessels were gently tunneled and anastomosed to the right facial vasculature. The flap inset was completed without complications. The patient's postoperative course was uneventful. The improvement of oral competence was successfully achieved (Fig. 5).

\section{Discussion}

It has been reported that various hand deformities can coincide with at least 127 different syndromes, such as Apert's, Pfeiffer or Nager Syndromes [14]. Therefore, finding an atypical thumb can be a predictor of other congenital anomalies $[15,16]$. The oculo-auriculo-vertebral spectrum patients including Goldenhar Syndrome may also present with limb deformities [17]. In our case with multiple facial deformities and delta phalanx of the thumb, we found a hypoplastic radial artery, arising from brachial bifurcation. Hypoplasia of the radial artery has been associated with congenital malformations such as Klippel-Feil, VATER, and Down's syndromes [18]. It also occurred in patients with isolated triphalangeal thumb [16]. It is well documented that certain vascular anomalies are linked with musculoskeletal deformities [18], although an association of a delta phalanx with radial hypoplasia and/or persistent median artery occurrence has not been reported. It has also never been reported in Goldenhar Syndrome.

Our patient presented with the persistent median artery, whose incidence is more common among the African Americans (up to 53\%) than Caucasians (2.5\% Polish, 4.3\% British) [7-11, 19]. The median artery in our case took origin from the most common location, the ulnar artery, although it has also been reported to arise from interosseous or radial arterial system [20]. It did not terminate, as in most cases, before entering the carpal tunnel [7]. As no peri-operative angiography was conducted, we are not able to determine whether the artery was contributing to the palmar arch formation or continuing as the palmar digital artery as described in the literature [7-11, 18]. Interestingly, $80 \%$ of patients with one persistent median artery, display the same anomaly on the other side [12]. In case of our patient, the anatomy of the contralateral non-syndromic right upper extremity was typical.

Based on our experience, we suggest that the vascular architecture must be meticulously studied preoperatively in case of congenital limb deformity, especially in the absence of contralateral flap. We propose that, when presence of the persistent median artery is suspected, the modified Allen's test should be performed first [5]. During modified Allen's test, compression of the hypothetical median vessel instead of the radial is applied [20]. If any suspicions arise, additional studies involving duplex Doppler ultrasound or magnetic resonance angiography are advised [20]. However, even normal pre-operative angiogram does not guarantee typical intra-operative findings [5].

When considering options for an alternative flap design, adequate hand perfusion should be assured first. Clearly, the surgeon should be well familiar with the anatomy of the forearm to avoid damage to neuromuscular structures while executing alternate dissection techniques. 
Fig. 4 Scheme of the patient's left forearm vasculature and delta phalanx of the left thumb

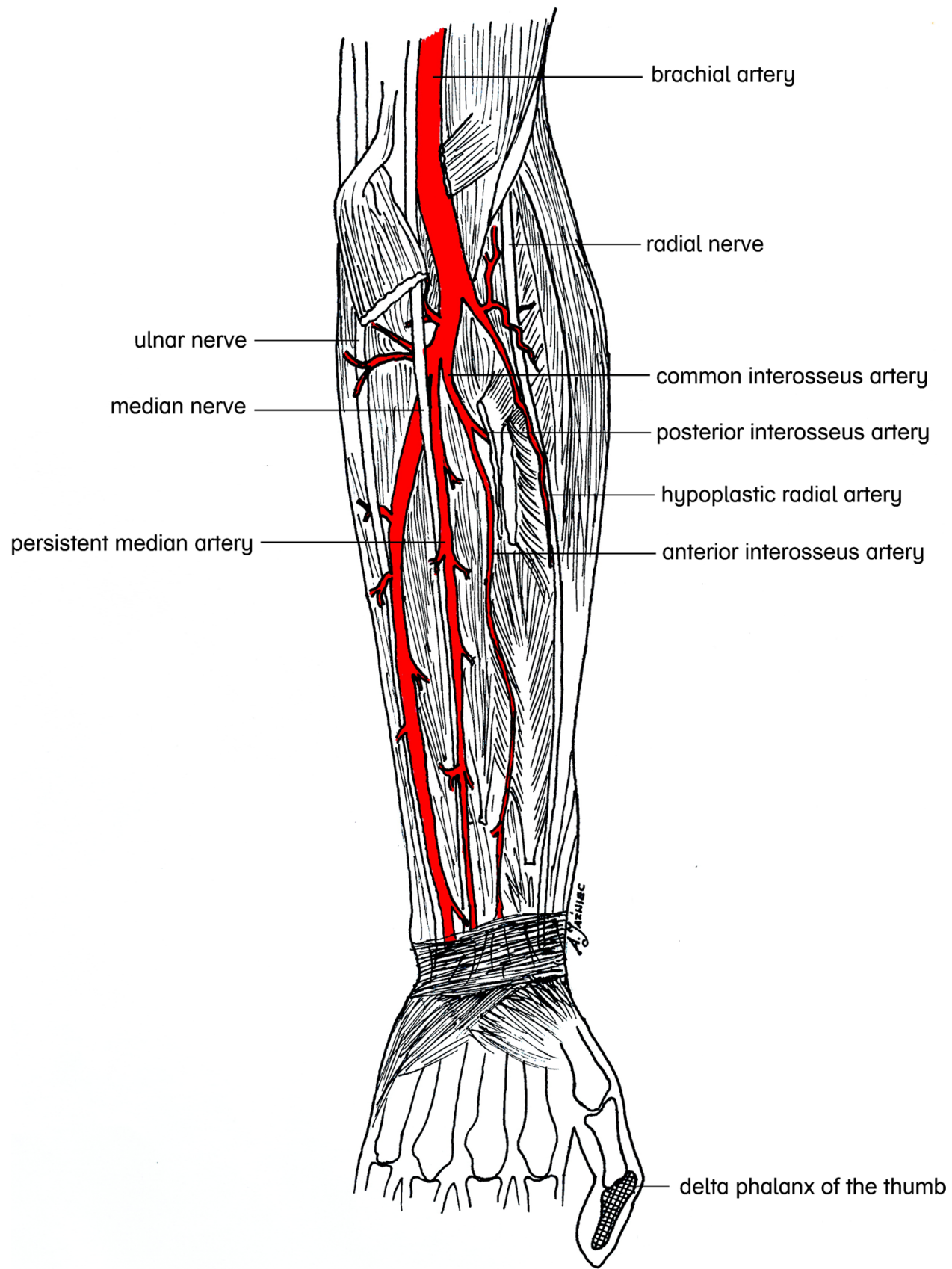

In our case, while approaching the presumed radial artery, we inadvertently ligated some of the perforators not realizing their abnormal origin. But after revealing the atypical anatomy, the remaining vessels, connecting the median artery and the skin paddle, were able to be preserved. Also, the septum was intact, so the intraoperative switch from radial to median artery flap was possible.
The possibility of similar adjustment from radial to ulnar been previously described [5]. We advocate that in face of an unusual hand anatomy, flexible flap creation techniques that allow a lifeboat strategy of redesigning the flap should be considered. artery forearm flap harvest, using the same skin island, has 


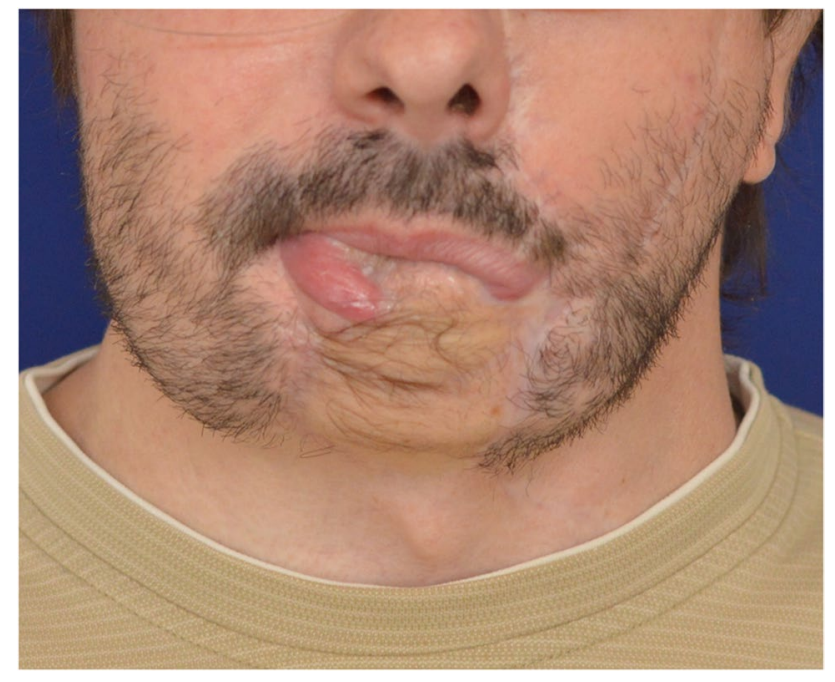

Fig. 5 Postoperative photograph of 32-year's old patient with Goldenhar Syndrome demonstrating improved lip closure and support

\section{Conclusions}

The surgeon seeking to use a skin flap from the forearm should always examine the upper extremity and employ pre-operative assessment techniques to delineate the anatomy of the forearm vessels if anatomic abnormalities are noted. Potentially "modifiable" flap design should be implemented in cases of congenital anomalies even if pre-operative studies appear unremarkable.

\section{Declarations}

Ethical approval This case report was conducted complying with the ethics requirements of the institutional research committee and with the 1964 Helsinski Declaration and its later amendments. No ethical approval was required for this case report.

Informed consent Informed consent was obtained from the patient included in this case study.

Patient consent Patient signed informed consent regarding publishing his data and photographs.

Conflict of interest Anna M. Jaźwiec and Ewa D. Komorowska Timek declare no conflict of interest.

Open Access This article is licensed under a Creative Commons Attribution 4.0 International License, which permits use, sharing, adaptation, distribution and reproduction in any medium or format, as long as you give appropriate credit to the original author(s) and the source, provide a link to the Creative Commons licence, and indicate if changes were made. The images or other third party material in this article are included in the article's Creative Commons licence, unless indicated otherwise in a credit line to the material. If material is not included in the article's Creative Commons licence and your intended use is not permitted by statutory regulation or exceeds the permitted use, you will need to obtain permission directly from the copyright holder. To view a copy of this licence, visit http://creativecommons.org/licenses/by/4.0/.

\section{References}

1. Timmons MJ (1986) The vascular basis of the radial forearm flap. Plast Reconstr Surg 77:80-92

2. Small JO, Millar R (1985) The radial artery forearm flap: an anomaly of the radial artery. Br J Plast Surg 38:501-503

3. Funk GF, Valentino J, McCulloch TM, Graham SM, Hoffman HT (1995) Anomalies of forearm vascular anatomy encountered during elevation of the forearm flap. Head Neck 17:284-292

4. Madaree A, McGibbon IC (1993) Anatomic variation in the blood supply of the radial forearm flap. J Reconstr Microsurg 9:277-279

5. Mordick TG (1995) Vascular variation of the radial forearm flap: a case report. J Reconstr Microsurg 11:345-346

6. Poteat WL (1986) Report of a rare human variation: absence of the radial artery. Anat Rec 214:89-95

7. Lippert H, Pabst R (1985) Arteries of the forearm. In: Lippert H, Pabst R, Munich JF (eds) Arterial Variations in Man. Springer Verlag, New York, p 71e3

8. George BJ, Henneberg M (1996) High frequency of the median artery of the forearm in South African newborns and infants. S Afr Med J 86:175e6

9. Coleman SS, Anson BJ (1961) Arterial patterns in the hand based upon a study of 650 specimens. Surg Gynecol Obstet 113:409e24

10. McCormack LJ, Cauldwell EW, Anson BJ (1953) Brachial and antebrachial arterial patterns: a study of 750 extremities. Surg Gynecol Obstet 96:43e54

11. Henneberg M, George BJ (1995) Possible secular trend in the incidence of an anatomical variant: median artery of the forearm. Am J Phys Anthropol 96:329e34

12. Woods SJ, Abrahams PH, Sanudo JR, Ferreira BJ (1997) Bilateral superficial radial artery at the wrist associated with a radial origin of a unilateral median artery. J Anat 189:691e3

13. Ding X, Wang X, Cao Y, Zhang J, Lin M, Fan X, Li J (2018) Goldenhar syndrome with blepharophimosis and limb deformities: a case report. BMC Ophthalmol 18(1):206

14. Rayan GM, Upton JIII (2014) Congenital Hand Anomalies and Associated Syndromes. Springer@ Springer-Verlag, Berlin

15. Potuijt JWP, Galjaard RH, van der Spek PJ, van Nieuwenhoven CA, Ahituv N, Oberg KC, Hovius SER (2018) A multidisciplinary review of triphalangeal thumb. J Hand Surg Eur

16. Schmitt E, Gillenwater JY, Kelly TE (1982) An autosomal dominant syndrome of radial hypoplasia, triphalangeal thumbs, hypospadias, and maxillary diastema. Am J Med Genet 13(1):63-69

17. Carry PM, Nguyen AK, Merritt GR, Ciarallo C, Chatterjee D, Park J, Miller NH, Scott FA (2018) Prevalence of persistent median arteries in the pediatric population on ultrasonography. J Ultrasound Med 37(9):2235-2224

18. Martín-Granizo R, Gómez F, Sánchez-Cuéllar A (2002) An unusual anomaly of the radial artery with potential significance to the forearm free flap. Case report. J Craniomaxillofac Surg 30(3):189-191

19. Acarturk TO, Tuncer U, Aydogan LB, Dalay AC (2008) Median artery arising from the radial artery: its significance during harvest of a radial forearm free flap. J Plast Reconstr Aesthet Surg 61(10):e5-e8

Publisher's note Springer Nature remains neutral with regard to jurisdictional claims in published maps and institutional affiliations. 